\title{
35-Cesaret ve korku- korkaklık kavramlarına Kültürdilbilimsel yaklaşım: Rusça ve Almanca örneği
}

\section{Hanife ERDOĞAN 1}

\section{Asuman YAPRAK2}

APA: Erdoğan, H.; Yaprak, A. (2020). Cesaret ve korku- korkaklık kavramlarına Kültürdilbilimsel yaklaşım: Rusça ve Almanca örneği. RumeliDE Dil ve Edebiyat Araştırmaları Dergisi, (21), 598607. DOI: $10.29000 /$ rumelide.835360.

\section{$\ddot{O} \mathbf{z}$}

Kültür taşıyıcısı kimliğiyle ön plana çıkan atasözleri, halk ruhunu ve bilincini özgün biçimde yansıtan kalıplaşmış ifadelerdir. Bu açıdan düşünüldüğünde atasözleri her toplumun milli dünya görüşüne ve deneyimlerine ayna tutmaktadır. Bu çalışmada ise atasözleri ışı̆̆ında Rus ve Alman toplumunun cesaret ve korku- korkaklık kavramlarına dair milli dünya görüşleri yansıtılmaya çalışılmıştır. Savaşlar silsilesiyle dolu tarihî bir geçmişe sahip olan ve II. Dünya Savaşı’nda karşı cephelerde kıyasıya savaşan Sovyet ve Alman toplumlarının cesaret ve korku- korkaklık kavramlarına dair bakış açısı merak uyandırmaktadır. Çalışmada atasözü ve kültür kuramı çerçevesinde, içinde cesaret ve korku- korkaklık kavramları olan Rusça ve Almanca atasözleri karşılaştırmalı bir biçimde ortaya koyulmuştur. Bu doğrultuda Rusça ve Almanca atasözleri sözlüklerinin incelenmesi sonucunda tespit edilen atasözleri gösterdikleri benzerlik ve farklılıklara göre tasnif edilmiştir. Çalışmada ele alınan cesaret ve korku- korkaklık kavramlarını içeren Rusça ve Almanca atasözlerinin anlam ve içerik açısından büyük ölçüde benzerlik gösterdiği sonucuna varılmıştır. Ayrıca genel itibariyle cesaretin övgüyle bahsedildiği, korku ve korkaklı̆̆ın ise aşağılandığı atasözlerine rastlanmıştır. Bununla birlikte atasözleri ışı̆̆ında Alman toplumunun, Rus toplumundan farklı olarak bilinçli ve kontrollü cesareti savunduğu tespit edilmiştir. Her iki toplumun atasözlerinde cesurca savaşmaya kutsiyet atfedilmesi ve tavşanın korkaklığı sembolize etmesi benzer sonuçlar arasındadır.

Anahtar kelimeler: Kültürdilbilim, Rusça-Almanca atasözleri, cesaret, korku - korkaklık

\section{The cultural linguistic approach to the concepts of courage and fear - cowardness: The case of Russian and German languages}

\footnotetext{
Abstract

The proverbs that stand out as cultural carriers are phrases that reflect the spirit and consciousness of the people in an original way. When considered from this point of view, proverbs reflect the national worldview and experience of every society. In this study, in the light of proverbs, the national world views of Russian and German society on the concepts of courage and fearcowardness will be revealed. Having a historical past, full of series of wars and fought fiercely on the opposite fronts during the World War II, Soviet and German societies have interesting courage and fear-cowardness concepts. Based on the proverbial and cultural theoretical framework, Russian and

1 Dr. Öğr. Gör., Kastamonu Üniversitesi, Turizm Fakültesi, Turizm ve Otel İşletmeciliği Bölümü (Kastamonu, Türkiye), h.erdogan@kastamonu.edu.tr, ORCID ID: 0000-0002-2760-765X [Araştırma makalesi, Makale kayit tarihi: 01.09.2020-kabul tarihi: 20.12.2020; DOI: 10.29000/rumelide.835360]

2 Öğgr. Gör., Kastamonu Üniversitesi, Yabancı Diller Yüksekokulu (Kastamonu, Türkiye), ayaprak@kastamonu.edu.tr, ORCID ID: 0000-0003-4179-4268 İstanbul Medeniyet Unive Turkish and Social Scinces Education, Turkish Language Teaching Kampüsü, Kartal-İstanbul/TÜRKIYE $\quad$ Education, Cevizli Campus, Kartal-İstanbul /TURKEY e-posta: editor@rumelide.com $\mid$ e-mail: editor@rumelide.com
} 


\begin{abstract}
German proverbs, which include the concepts of courage and fear, were presented by analyzing the national world view of both cultures in a comparative manner. In this direction, the proverbs determined as a result of the examination of Russian and German proverbs dictionaries were classified according to the similarities and differences they show. As a result of the study, it was concluded that the Russian and German proverbs, which include the concepts of courage and fearcowardness are largely similar in terms of meaning and content. In addition, proverbs in which courage is praised and fear and cowardness are humiliated were found. However, unlike Russian society, it was found that German society advocates conscious and controlled courage in the light of proverbs. Among similar consequences are the proverbs of both societies attributing holiness to fighting bravely and the rabbit symbolizing cowardness.
\end{abstract}

Keywords: Cultural linguistic, Russian and German proverbs, courage, fear - cowardness

\title{
Giriş
}

Halk kültürünün, halk psikolojisinin ve felsefesinin bir aynası olarak dil, milli tarihin ve maneviyatın tek bir kaynağı olarak algılanmıştır. XVIII. yüzyılda ve XIX. yüzyılın başlarında J. G. Herder ve V. Humboldt gibi bilim insanları dilin yapısal özelliğinin halk kültürü, psikolojisi ve sanatına etki ettiğini ortaya koymuştur (Tolstoy, 1990: 238). Bireysel dilleri sosyal ve toplumsal olgularla yakından ilişkili bulmuştur. Dilin "entelektüel ve ahlaki varlığı" etkilediğini, "ulusların ruhunu" veya "ulusal karakteri" şekillendirdiğini ve kültürel gelişim durumu üzerine bir yargıya varılabileceğini düşünmüşlerdir (Karstedt, 2004: 46). Humboldt, dil ve ulusal karakter arasındaki yakın ilişki nedeniyle, dilin kültürel özelliklerinin tanımlanmasında ve analizinde olağanüstü bir rol oynadığını belirtmiştir (Humboldt, 1880: 210). Dili, "halkların ruhunun dış görünüşü; dilleri ruhları ve ruhları ise dilleridir" olarak tanımlamıştır (Humboldt, 1995: 8). Herder ise, dili "bir halkın düşünce varlı̆̆ı" olarak ifade etmiştir (Herder, 1877: 13). Herder ve Humboldt'un fikirleri bu bağlamda dilbilim literatüründe evrensel kabul görmüştür.

Rus dilbiliminde ise Humboldt gibi A.A. Potebnya da dildeki düşünceyi üreten mekanizmayı görmüştür. Potebnya, halkı dilin yaratıcısı olduğunu belirterek, halk ruhunun ürünü olduğunu savunmuştur. Dilin, münferit bir olgu olmadığının, halk kültürüne sıkı sıkıya bağlı olduğunun altını çizmiştir (Potebnya, 1989: 5). Süregelen ifadeler çerçevesinde dili, kültürden, tarihten ayrı düşünmenin mümkün olmadığı belirtilmiştir. S. G. Ter- Minasova, dil ve kültür arasındaki sıkı bağı şu cümleleriyle ifade etmiştir: "Dil, kültürün aynasıdır. Dilde sadece insanı çevreleyen gerçek dünya ve insan yaşamının gerçek şartları değil, aynı zamanda halkın sosyal bilinci, mantalitesi, milli karakteri, yaşam biçimi, gelenek ve görenekleri, ahlakı, değerler dizgesi, mizacı ve dünya görüşü de yansitılmaktadır. Dil, kültürün hazinesi, deposu ve kumbarasıdır. Dil, söz varlığında, gramerde, mecazlarda, atasözlerinde, folklorda, edebi ve bilimsel eserlerde, yazılı ve sözlü anlatımlarda kültürel değerleri barındırmaktadır" (Ter- Minasova, 2000: 13,14). Bu ifade kapsamında çalışmanın konusu olan her bir atasözü herhangi bir milletin kültürel kodlarını çözümlemesine yardımcı olarak söz konusu milletin dil dünya görüşünün perdesini aralamaktadır.

Dil, milli karakteri ve halk bilincini tanımak için büyük imkân tanımaktadır. Dil dünya görüşü, dil merceğinden geçerek insanın bilincinde şekillenmekte ve dil toplumunun yaşam şartlarına, doğaya, iklime, halkın geçtiği tarihsel yola ve diğer unsurlara bağlı kalmaktadır (Basko, 2019: 347). Bu bağlamda "dil kültüre en sıkı biçimde bağlıdır: dil kültürde yetişir, dilde gelişir ve kültürü ifade etmektedir. Bu fikrin temelinde, 1990'lı yıllarda şekillenen dilbilimin özgün bir dalı olarak kabul edilen

\footnotetext{
Adres $\mid$ Address

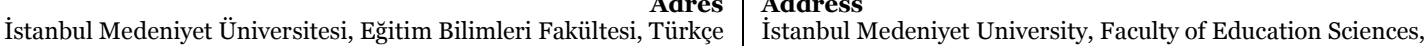
ve Sosyal Bilimler Eğitimi Bölümü, Türkçe Eğitimi ABD Cevizli Turkish and Social Scinces Education, Turkish Language Teaching Kampüsü, Kartal-İstanbul/TÜRKIYE $\quad$ Education, Cevizli Campus, Kartal-İstanbul /TURKEY e-posta: editor@rumelide.com 1 e-mail: editor@rumelide.com
} 
kültürdilbilim adında yeni bir bilim ortaya çlkmıştır. Kültürdilbilim dile yerleşmiş ve dile yansıyan halk kültürünün tezahürlerini araştıran, dilbilim ve kültürbilimin eşiğinde ortaya çıkan, dilbilimin bir dalı olarak tanımlanmıştır (Maslova, 2001: 9). Kültürdilbilimi, dili kültürel ve dilsel olgu olarak açıklayan, dilbilim alanını sosyal iletişim alanlarını incelemek için kullanan, dilbilimsel araştırmalarını kültürlerarası iletişim ve öğrenme konularında ele alan bir dilbilim alanıdır (Kuße, 2012: 13). Bir başka deyişle doğrudan milli dünya görüşünün, dil bilincinin, zihinsel ve dilsel bütünün özelliklerinin incelenmesiyle ilintili olarak, dilde ve söylemde kültürün yansımasını, görüntüsünü inceleyen bir disiplindir (Krasnıh, 2002: 12).

Kültürdilbilimin araştırma konularından biri olan atasözleri, toplumun zihniyeti ve kültürü, milli karakteri ve tutumu hakkında bilgi veren önemli bir kaynaktır. Atasözleri toplumun milli dünya görüşünü yansıtmaktadır. Milli dünya görüşü, sadece bireysel değil aynı zamanda kitlesel bir olgu olarak dünya görüşünü ifade eden, bireysel ve toplumsal bilinçte şekillenen özgün dil içi bir gerçekliği ifade etmektedir (Alefirenko ve Semenenko, 2009: 310). Bu bağlamda çalışmada Rusça ve Almanca atasözleri incelenerek cesaret ve korku- korkaklık çerçevesinde her iki kültürün milli dünya görüşünün ortaya koyulması amaçlanmıştır. $\mathrm{Bu}$ amaçtan yola çıkarak içinde cesaret ve korku- korkaklık kavramlarını barındıran Rusça ve Almanca atasözleri anlambilim ve kültür bilim açısından ele alınmıştır. Çalışmanın konusu olarak cesaret ve korku- korkaklık kavramlarının seçilmesinin temelinde, savaşlarla dolu bir tarihe sahip olan özellikle II. Dünya Savaşı'nda cephelerde kıyasıya savaşan Sovyetler Birliği ve Alman toplumunun cesarete ve korkaklığa dair milli dünya görüşü merak uyandırmıştır. Çalışmada bileşen analiz yöntemi, semantik yöntem ve karşılaştırmalı yöntem kullanılmıştır.

\section{Atasözü ve kültür}

Rus dilbiliminde atasözü kavramına poslovitsa ve pogovorka terimleri karşllı gelmektedir. Türkçe karşılıkları atasözleri olan poslovitsa ve pogovorka birbirinden farklıdır. Poslovitsa yapı olarak her zaman cümle halinde iken; pogovorka cümle biçiminde olabileceği gibi kelime grubu şeklinde de olabilir (Alefirenko ve Semenenko, 2009: 240). Ayrıca pogovorka, poslovitsaya göre farklı yaşam olgularının duygu değerlerini daha güçlü vermektedir. Pogovorka öncelikle konuşan kişinin duygularını ifade etmek için konuşmada yer almaktadır Poslovitsa geniş anlamıyla hem gerçek hem mecazî anlama sahip olan ya da sadece mecazî anlamı olan ve gramer açısından bitmiş cümle yapısındaki kısa halk ifadeleridir. Pogovorka ise poslovitsadan farklı olarak sadece gerçek anlama sahiptir (Jukov, 1991: 7-11). Alman literatüründe ise bugün atasözü anlamında kullanılan Sprichwort terimi için, Eski Yüksek Almancada Biscaft, Bispel ve Biwort ve Orta Yüksek Almancada ise Altez, Altsprochen, Gemeinez Wort kavramları kullanılmıştır. Genel olarak Sprichwort kelimesinin Orta Yüksek Almanca Spriche ve Wort kelimelerinden oluştuğu ve "çok konuşulan/kullanılan kelime" anlamına geldiği kabul görmüştür (Röhrich ve Mieder, 1977: 1).

Atasözleri kültürle yakından ilişkili olup, kültürel uygulama ve değerleri içermekte ve aktarmaktadır. Bu bağlamda atasözleri sadece dilsel birer öge olmayıp daha çok bir kültürün dilsel sembolü olarak görülmüştür. Aforist Peter Sirius atasözlerini "yaşam deneyimi ansiklopedisi" olarak tanımlamaktadır (Frey, 2017: 7). Atasözleri derin düşünce ve geniş kapsamlı bir içeriği, tek sözle güzel bir şekilde ifade etme biçimidir. Halkın kıvrak zekâsı, sosyal hayattaki çeşitli olaylar, doğal değişmeler ve insanoğlunun içinde bulunduğu durum atasözlerinde yankı bulmuştur. İnsanlık, davranış, karakter, eğitim, öğretim gibi çeşitli konular üzerine genel çıkarımların vuku bulmuş halidir. (Ahanov, 2013: 175). Bir başka deyişle atasözleri, özünde dile getirilmiş bir yaşam kuralı veya genelleştirilmiş yaşam deneyimi içeren,

\footnotetext{
\begin{tabular}{r|l} 
Adres & $\begin{array}{l}\text { Address } \\
\text { İstanbul Medeniyet Üniversitesi, Eğitim Bilimleri Fakültesi, Türkçe }\end{array}$ \\
İstanbul Medeniyet University, Faculty of Education Sciences,
\end{tabular} ve Sosyal Bilimler Eğitimi Bölümü, Türkce Eğitimi ABD Cevizli Turkish and Social Scinces Education, Turkish Language Teaching Kampüsü, Kartal-İstanbul/TÜRKIYE Education, Cevizli Campus, Kartal-İstanbul /TURKEY e-posta: editor@rumelide.com $\mid$ e-mail: editor@rumelide.com
} 
yaygın, sabit ve kalıı olarak şekillenmiş ifadelerdir. Atasözleri, karmaşık ifadeleri içerisinde ve kusursuz biçimleriyle, bazen büyük şiirsel cazibenin minyatür metinlerine dönüşürler (Beyer ve Beyer, 1989: 6). Atasözleri, herhangi bir toplumun deneyimlerini özgün ifadelerle kayıt altına alan, uzak ya da yakın tarihin maddi ve manevi geçmişine ışık tutan, kültürel mirasın aktarıcısı niteliğinde ifadelerdir.

Atasözleri üzerine Rus ve Alman literatüründe özgün tanımlamalar yapılmıştır. Sözlükbilimci kimliğiyle ön plana çıan Dal', atasözlerini "halk bilgeliğinin ve akıl yürütmesinin kitabı, bir inleyiş, bir nefes, bir ağlama ve hıçkırarak ağlama, mutluluk ve neşe, yüzlerdeki acı ve teselli; bu halk aklının, özgün endamının rengi, yaşayan bir halk gerçeğidir, kimsenin yargılanmadığı kendi soyunun yasa kitabı" olarak tanımlamıştır. A.S. Puşkin atasözleri için "bu nasıl bir görkem, bu nasıl fikir, bizim her atasözümüzde nasıl bir anlam, nasıl bir altın!.. demiştir (Kuznetsova, 1964: 2-3). N.V. Gogol ise atasözü üzerine "Bizim atasözlerimizde kendi aracıyla ironi, alay, görsellik, pitoresk tasvirin kesinliğini ortaya koyabilen halk aklının sıra dışı doluluğu görünmektedir...” ifadesinde bulunmuştur (Gogol, 1952: 369). Almancada bilimsel olarak atasözlerini ilk kez ele alan Friedrich Seiler ise atasözlerini "halk içinde yaygın, öğretici bir eğilime ve seçkin biçime sahip kendi kendine yeten sözler" olarak tanımlamıştır (Seiler, 1918: 2). Matti Kuusi atasözünü "insan anıtı" olarak tanımlayarak insanı veya bulunduğu toplumu yansıtan, bireyi açıklayan sözler anlamına getirmektedir (Kuusi, 1957: 52). Hermann Bausinger atasözünü "kısmen geçerli bir yaşam kuralı" olarak tanımlamıştır (Bausinger, 1968: 98).

Çalışma konusunun odağında olan korku-korkaklık ve cesaret üzerine ele alınacak atasözlerinde geçen bu kavramların Rusça ve Almanca karşılıklarını vermek yerinde olacaktır. Rusça sözlükte korku ve korkaklık anlamında cmpax (strah) ve mpycocmь (trusost') sözcükleri; cesaret, yiğitlik anlamında ise отвага (otvaga), мужество (mujestvo), смелость (smelost'), храбрость (hrabrost') sözcükleri kullanılmaktadır. L. V. Savenkova Rus zihniyetinde iki tür cesaretin (smelost) olduğunu ileri sürmüştür. İnsan her defasında "cesaret gösterir" yani aktif olarak bir davranışa karar verir, ancak bu kararlılık ya bulunduğu davranışın mertliği bilinciyle ya da kişisel bir çıkara, menfaate ulaşma isteğidir. İlk türdeki cesaret kişinin ahlaki davranışa inancıyla desteklenirken; ikinci türdeki cesaret laubaliliğe, küstahlı̆̆a yakın olarak görülmüsstür (Golovnya ve Çjan, 2012: 63). Almancada ise cesaret anlamında Mut, Tapferkeit, Courage, Kühnheit sözcükleri kullanılırken; korkaklık anlamında Angst, Furcht, Scheu, Schreck sözcükleri kullanılmaktadır. Gustav Radbruch'a göre iki tür cesaret vardır. Birincisi korku bilmeyen soğukkanlılıktır (Kühnheit); bu ruhtan çok sinirle ilgilidir ve bu nedenle etik olarak belirsizdir. İkinci tür ise cesarettir (Mut), ilk önce korkuyu bastırmak zorundadır ve bu nedenle bir özgürlük eylemi olduğu için ahlaki değerlendirmeye tabidir; sadece bu ikinci tür cesaret, Radbruch'a göre içerik yönünden "cesaret" adını tam anlamıyla hak etmektedir (Kaufmann, 1991: 3) . Çalışmada atasözleri merceğinden Alman ve Rus toplumunun cesaret, korku ve korkaklık kavramlarına dair milli dünya görüşü ortaya koyulmaya çalışılacaktır.

\section{Cesaret ve korku-korkaklık bağlamında Rusça ve Almanca atasözleri}

Bu çalışmada Rusça cesaret ve korku- korkaklık anlamındaki atasözleri için V.İ. Dal tarafından hazırlanan Rus Halkinin Atasözleri (Poslovitsı Russkogo Naroda), A. M. Jigulev ve N. P. Kuznetsov tarafından hazırlanan Vatan İçin Ölümüne Savun. SSCB Ülkelerinin Atasözleri ( Za Kray Svoy Nasmert' Stoy. Poslovitsı i Pogovorki Narodov SSSR), V.P. Jukov tarafından hazırlanan Rusça Atasözleri Sözlüğü (Slovar’ Russkih Poslovits i Pogovorok), A. Kuznetsova tarafından hazırlanan Atasözü Olmadan Söz Söylenemez. Rusça Atasözleri Derlemesi (Bez Poslovitsı Reç ne Molvitsya. Sbornik Russkih Poslovits), M. A. Rıbnikova tarafından hazırlanan Rus Atasözleri (Russkie Poslovitsı i

\footnotetext{
Adres

İstanbul Medeniyet Üniversitesi, Eğitim Bilimleri Fakültesi, Türkçe İstanbul Medeniyet University, Faculty of Education Sciences,

ve Sosyal Bilimler Eğitimi Bölümü, Türkçe Eğitimi ABD Cevizli $\quad$ Turkish and Social Scinces Education, Turkish Language Teaching Kampüsü, Kartal-İstanbul/TÜRKIYE Education, Cevizli Campus, Kartal-İstanbul /TURKEY e-posta: editor@rumelide.com $\mid$ e-mail: editor@rumelide.com
} 
The cultural linguistic approach to the concepts of courage and fear - cowardness: The case of Russian and German languages / H. Erdoğan; A. Yaprak (pp. 598-607)

Pogovorki), M. Şahnoviç tarafından hazırlanan Rus Halkının Askerî Atasözleri (Voennıe Poslovitsı Russkogo Naroda), Yu. V. Bodrova tarafından hazırlanan Rusça Atasözleri ve İngilizce Benzerleri (Russkie Poslovitsı i Pogovorki i ih Angliyskie Analogi) adlı çalışmalarda bulunan cesaret, korkukorkaklık ile ilgili atasözleri taranarak Türkçeye aktarılmıştır. Almancada ise cesaret ve korkukorkaklık anlamına gelen atasözleri için Horst ve Annelies Beyer tarafından derlenen Atasözleri Sözlüğü (Sprichwörterlexikon), Joe H. Kirchbeger tarafından hazırlanan Büyük Atasözleri Kitabı (Das Grosse Sprichwörter Buch) ve Heinrich Leineweber tarafından hazırlanan Bilgeliğin Peşinde: Atasözlerinin ve atasözü olarak kullanılan deyimlerin derlenmesi ve açıklanması (Die Weisheit auf der Gasse: Zusammenstellung und Erklärung von Sprichwörtern und sprichwörtlichen Redensarten) adlı çalışmalar taranarak Türkçeye aktarılmıştır. Tespit edilen bu atasözlerinden Rusça ve Almanca benzerlik ile farklılık gösterenler seçilerek, tasnif edilmeye çalışılmıştır.

Tablo 1. Benzerlik gösteren Rusça - Almanca atasözleri

\begin{tabular}{|c|c|}
\hline Rusça & Almanca \\
\hline $\begin{array}{l}\text { Смелость (отвага) города берет (Rıbnikova, 1961: } \\
\text { 72; Jukov, 1991: 307). } \\
\text { (Smelost (otvaga) goroda beret). } \\
\text { Cesaret şehri alır. }\end{array}$ & $\begin{array}{l}\text { Wer nichts wagt, kommt nicht nach Spandau } \\
\text { (Kirchberger, 1986: 114). } \\
\text { Cesaret etmeyen Spandau'a ulaşamaz. } \\
\text { Ein feiger Mann gewinnt keine Stadt } \\
\text { (Beyer ve Beyer, 1989: 173). } \\
\text { Korkak adam bir şehir kazanamaz. }\end{array}$ \\
\hline $\begin{array}{l}\text { Без отваги нет победы (Jigulev ve Kuznetsov, } \\
\text { 1974:45). } \\
\text { (Bez otvagi net pobedi). } \\
\text { Cesaret olmadan zafer olmaz. } \\
\text { Храбрость и умение рождают победу (Şahnoviç, } \\
\text { 1945: 24). } \\
\text { (Hrabrost' i umenie rojdayut pobedu). } \\
\text { Cesaret ve beceri zaferi doğurur }\end{array}$ & $\begin{array}{l}\text { Wer wagt, gewinnt (Beyer ve Beyer, 1989: 113). } \\
\text { Cesaret eden kazanir. } \\
\text { Wer nicht wagt, der nicht gewinnt } \\
\text { (Beyer ve Beyer, 1989: } 326 \text { ). } \\
\text { Cesaret etmeyen kazanamaz. }\end{array}$ \\
\hline $\begin{array}{l}\text { Волка бояться , так и в лес не ходить (Dal, } \\
\text { 2008: 183). } \\
\text { (Volka boyatsya, tak iv les ne hodit.) } \\
\text { Kurttan korkuyorsan ormana gitme. } \\
\text { Лягушек бояться- в реке не купаться } \\
\text { (Ribnikova, 1961: } 73 \text { ). } \\
\text { (Lyaguşek boyatsya- } v \text { reke ne kupatsya). } \\
\text { Kurbağadan korkuyorsan nehirde yüzme. }\end{array}$ & $\begin{array}{l}\text { Wer sich vor Blättern fürchtet, muss nicht in } \\
\text { den Wald gehen (Beyer ve Beyer, 1989: } 57 \text { ). } \\
\text { Yapraklardan korkan, ormana girmek zorunda } \\
\text { değildir. } \\
\text { Wer das Feuer scheut, muss kein Schmied } \\
\text { werden (Beyer ve Beyer, 1989: 223). } \\
\text { Ateşten korkan demirci olmak zorunda değildir. } \\
\text { Wer aufs Meer geht, darf die Wellen nicht } \\
\text { fürchten (Beyer ve Beyer, 1989: 98). } \\
\text { Denize giren dalgalarindan korkmamalı. }\end{array}$ \\
\hline $\begin{array}{l}\text { Медведя бояться, так ягод не видать } \\
\text { (Rıbnikova, 1961: 73). } \\
\text { (Medvedya boyatsyai tak yagod ne vidat). } \\
\text { Ayıdan korkarsan, yemiş göremezsin. }\end{array}$ & $\begin{array}{l}\text { Wer das Wasser fürchtet, lernt nie } \\
\text { schwimmen (Beyer ve Beyer, 1989: 98). } \\
\text { Sudan korkan hiçbir zaman yüzmeyi öğrenemez. } \\
= \\
\text { Wer das Laub fürchtet, bleibt aus dem Walde } \\
\text { (Beyer ve Beyer, 1989: 98). } \\
\text { Yapraklardan korkan ormandan geri kalır. }\end{array}$ \\
\hline $\begin{array}{l}\text { Кто боится воробьев, тот не сеет проса } \\
\text { (Rıbnikova, 1961: 75). } \\
\text { (Kto boitsya vorob'ev, tot ne seet prosa). } \\
\text { Serçelerden korkan, darı ekmez. }\end{array}$ & $\begin{array}{l}\text { Wer den Rauch fürchtet, kommt nicht zum } \\
\text { Feuer (Beyer ve Beyer, 1989: 151). } \\
\text { Dumandan korkan ateşe gidemez. } \\
= \\
\text { Wer jede Wolke fürchtet, taugt nicht zum } \\
\text { Bauern (Kirchberger, 1986: 45). } \\
\text { Her buluttan korkan çiftçi olamaz. }\end{array}$ \\
\hline $\begin{array}{l}\text { Трусливому каждый шорох- беда (Rıbnikova, } \\
\text { 1961: 75). } \\
\text { (Truslivomu kajdıy şoroh- beda). }\end{array}$ & $\begin{array}{l}\text { Dem Furchtsamen rauschen alle Blätter } \\
\text { (Kirchberger, 1986: 45). } \\
\text { Korkana tüm yapraklar hışırdar. }\end{array}$ \\
\hline
\end{tabular}

1961: 75).
(Truslivomu kajdıy şoroh- beda).

Korkana tüm yapraklar hışırdar. 


\begin{tabular}{|c|c|}
\hline orkağa her hışırtı sıkıntıdır. & \\
\hline $\begin{array}{l}\text { Храбрость бережет бойца (Şahnoviç, 1945: 24). } \\
\text { (Hrabrost' berejet boytsa). } \\
\text { Cesaret savaşçıу korur. } \\
= \\
\text { Oтвага бережет воина (Şahnoviç, 1945: 25). } \\
\text { (Otvaga berejet voina). } \\
\text { Yiğitlik askeri korur. }\end{array}$ & $\begin{array}{l}\text { Kühner Mut ist der beste Harnisch (Leineweber, } \\
\text { 2018: } 50 \text { ). } \\
\text { Korkusuz cesaret en iyi zirhtır. }\end{array}$ \\
\hline $\begin{array}{l}\text { Удалой долго не думает. Отвага- половина } \\
\text { спасенья (Dal, 2008: 182). } \\
\text { (Udaloy dolgo ne dumaet. Otvaga-polovina spasenya) } \\
\text { Babayiğit uzun uzun düşünmez. Yüreklilik kurtuluşun } \\
\text { yarısıdır. }\end{array}$ & $\begin{array}{l}\text { Wagen macht gewinnen, zagen macht } \\
\text { zerrinnen (Beyer ve Beyer, 1989: } 339 \text { ). } \\
\text { Cesaret kazandırır, tereddüt eritir. }\end{array}$ \\
\hline $\begin{array}{l}\text { У страха глаза велики (Rıbnikova, 1961: 75). } \\
\text { (U straha glaza veliki). } \\
\text { Korkunun gözleri büyüktür. }\end{array}$ & $\begin{array}{l}\text { Die Furcht hat grosse Augen (Beyer ve Beyer, 1989: } \\
\text { 43). } \\
\text { Korkunun büyük gözleri vardır. }\end{array}$ \\
\hline $\begin{array}{l}\text { Бояться смерти- на свете не жить (Dal, 2008: } \\
\text { 183; Bodrova, 2007: 128). } \\
\text { (Boyatsya smerti- na svete ne jit.) } \\
\text { Ölümden korkmak, dünyada yaşamamaktır. }\end{array}$ & $\begin{array}{l}\text { Was nützt das Leben dem, der stets vor dem } \\
\text { Tode zittert (Beyer ve Beyer, 1989: 161). } \\
\text { Ölümden korkana hayat ne işe yarar. }\end{array}$ \\
\hline $\begin{array}{l}\text { На трусливого много собак. На смелого } \\
\text { собака лает, а трусливого рвет (Dal, 20o8: 184). } \\
\text { (Na truslivogo mnogo sobak. Na smelogo sobaka laet, } \\
\text { a truslivogo rvet.) } \\
\text { Korkağa köpek çok. Köpek cesura havlar, korkağı ise } \\
\text { parçalar. }\end{array}$ & $\begin{array}{l}\text { Wer keine Angst hat, dem tun die Hunde auch } \\
\text { nichts (Beyer ve Beyer, 1989: 38). } \\
\text { Korkmayana köpekler de bir şey yapmaz. }\end{array}$ \\
\hline $\begin{array}{l}\text { Смелый приступ- не хуже победы (Rıbnikova, } \\
\text { 1961: 72). } \\
\text { (Smeliy pristup-ne huje pobedi). } \\
\text { Cesur hücum zaferden kötü değildir }\end{array}$ & $\begin{array}{l}\text { Frisch gewagt ist halb gewonnen } \\
\text { (Beyer ve Beyer, 1989: 123). } \\
\text { Cesaret etmek yarı kazanmaktır. }\end{array}$ \\
\hline
\end{tabular}

Diğer toplumlarda olduğu gibi Rus ve Alman toplumunda da cesaretin zafer kazanmada başat bir rol üstlendiği; korku ve korkaklığın ise yenilgiyi beraberinde getirdiği genel kabul görmüştür. Dikkat çeken nokta ise her iki toplumun atasözleri anlam ve içerik bakımından birbirine çok benzediği sonucudur.

Tablo 2 - Hayvan sembolleri içeren atasözleri

\begin{tabular}{|l|l|}
\hline Rusça & Almanca \\
\hline $\begin{array}{l}\text { Заяц от листа, а лягушка от зайца бежит (Dal', } \\
\text { 2008: 186). } \\
\text { (Zayats ot lista, a lyaguşka ot zaytsa bejit). } \\
\text { Tavşan yapraktan, kurbağa tavşandan kaçar. }\end{array}$ & $\begin{array}{l}\text { Schrecken jagt den Hasen aus dem Busch } \\
\text { (Beyer ve Beyer, 1989: 241). } \\
\text { Korku, tavşanı çalıdan kovalar. }\end{array}$ \\
\hline $\begin{array}{l}\text { Заяц самого себя боится (Rıbnikova, 1961: 75). } \\
\text { (Zayats samogo sebya boitsya). } \\
\text { Tavşan kendisinden korkar. }\end{array}$ & $\begin{array}{l}\text { Ein erschrockener Hase ist selbst im Himmel } \\
\text { nicht sicher. } \\
\text { (Kirchberger, 1986: 37) } \\
\text { Korkmuş bir tavşan cennette bile güvenli değildir. }\end{array}$ \\
\hline $\begin{array}{l}\text { Соколу лес не страшен (Rıbnikova, 1961: 73). } \\
\text { Sokolu les ne straşen). } \\
\text { Şahine orman korkunç değildir. }\end{array}$ & $\begin{array}{l}\text { Сердце coколье, а смелость (смельство) } \\
\text { воронье (Dal, 2008: 185) } \\
\text { (Serdtse sokolye, a smelost (smelstvo) voronye). } \\
\text { Кalp şahinin, cesaret ise karganın. }\end{array}$ \\
\hline
\end{tabular}

Yukarıdaki tabloya bakıldığında her iki dilde de tavşan korkuyu imgelemektedir. Tavşan, hızlı olması ve hızlı üremesi nedeniyle doğurganlığı, erotizmi ve saflı̆̆ı temsil etmekle birlikte; gözleri açı olarak uyuduğuna inanılan tavşan ayrıca korkaklığı, kurnazlığı ve sinsiliği sembolize etmektedir. 16. ve 17.

\footnotetext{
\begin{tabular}{r|l} 
Adres & $\begin{array}{l}\text { Address } \\
\text { İstanbul Medeniyet Üniversitesi, Eğitim Bilimleri Fakültesi, Türkçe }\end{array}$ \\
İstanbul Medeniyet University, Faculty of Education Sciences,
\end{tabular} ve Sosyal Bilimler Eğitimi Bölümü, Türkce Eğitimi ABD Cevizli $\quad$ Turkish and Social Scinces Education, Turkish Language Teaching Kampüsü, Kartal-İstanbul/TÜRKIYE $\quad$ Education, Cevizli Campus, Kartal-İstanbul /TURKEY e-posta: editor@rumelide.com 1 e-mail: editor@rumelide.com
} 
The cultural linguistic approach to the concepts of courage and fear - cowardness: The case of Russian and German languages / H. Erdoğan; A. Yaprak (pp. 598-607)

yüzyılda tavşan yüreksiz ve korkak insanı imgelemeye başlamıştır (Butzer ve Jacob, 2008: 148). Ayrıca Rusçada şahin ve karga korkusuzluğun, cesaretin imgesi olarak kullanılmıştır. Şahin, üstünlüğün, güçlü isteğin, ruhun, ışığın ve özgürlüğün simgesidir. Aynı zamanda kartal gibi zaferin sembolü olarak kullanılmıştır (Tresidder, 1999: 347). Karga ise kötülüğün karanlığı, savaşın tahribi, günahın, gücün sembolü olmakla birlikte Kelt döneminde savaşın tanrıçalarını sembolize etmektedir (Kuper: 1995:45).

Tablo 3. Cesaret - mutluluk bağlantılı atasözleri

\begin{tabular}{|l|l|}
\hline Rusça & Almanca \\
\hline Счастье всегда на стороне отважных & Dem Feigen zeigt das Glück den Rücken (Beyer ve \\
(Şahnoviç, 1945: 25). & Beyer, 1989: 83). \\
(Sçast'ye vsegda na storone otvajnıh). & Şans korkağa sirtını gösterir. \\
Mutluluk her zaman cesurlardan yanadır. & \\
\hline
\end{tabular}

Yukardaki atasözlerine bakıldığında her iki toplumda da mutluluk, şans gibi olguların cesurlardan yana olduğu belirtilerek her iki toplumun atasözlerinde benzer durum ortaya koyulmuştur.

Tablo 4. Kutsiyet atfedilen Rusça - Almanca atasözleri

\begin{tabular}{|l|l|}
\hline Rusça & Almanca \\
\hline Бой - святое дело: иди на врага смело (Jigulev ve & War keinen Mut hat, hat keine Religion \\
Kuznetsov, 1974: 8). & (Kirchberger, 1986: 83). \\
(Boy- svyatoe delo: idi na vraga smelo). & Cesareti olmayanın dini olmaz. \\
Muharebe kutsal bir konudur: düşmanına cesurca yürü. & $\begin{array}{l}\text { Dem Mutigen hilft Gott. } \\
\text { ((Leineweber, 2018: 50). } \\
\text { Cesura tanrı yardım eder. }\end{array}$ \\
\hline
\end{tabular}

Yukarda verilen atasözleri kapsamında, cesaret ve muharebe konusuna kutsiyet atfedildiğini söylemek mümkündür. Bu durum ise savaşçılara dini boyutta da savaşmaya teşvik etmiş ve yüreklendirmiştir.

Tablo 5. Alman ve Rus toplumunda korkaklık bağlamında farklılık gösteren atasözleri

\begin{tabular}{|c|c|}
\hline Rusça & Almanca \\
\hline $\begin{array}{l}\text { Никого (Ничего) не боюсь: Только Бога боюсь. Никого не бойся, } \\
\text { только Бога бойся!(Dal, 2008: 183). } \\
\text { (Nikogo (Niçego) ne boyus: Tolko Boga boyus. Nikogo ne boysya, tolko Boga } \\
\text { boysya) } \\
\text { Hiç kimseden (hiçbir şeyden) korkmuyorum. Sadece Tanrı'dan korkarım. } \\
\text { Kimseden korkma, sadece Tanrı'dan kork. }\end{array}$ & $\begin{array}{l}\text { Fürchte, die dich } \\
\text { fürchten } \\
\text { (Kirchberger, 1986: 45). } \\
\text { Senden korkanlardan kork. }\end{array}$ \\
\hline $\begin{array}{l}\text { Лучше быть мертвым героем; чем живым трусом (Jigulev ve Kuznetsov, } \\
\text { 1974: 19). } \\
\text { (Luçşe but mertvım geroem; çem jüım trusom) } \\
\text { Sağ korkak olmaktansa ölü kahraman olmak daha iyidir. } \\
\text { Герой умирает однажды, трус -тысячу раз (Bodrova, 2007: 25). } \\
\text { (Geroy umiraet odnajd, trus- tısyaçu raz) } \\
\text { Kahraman bir kez ölür, korkak bin kez. } \\
\text { Лучше умирать в поле, да не в яме! (Dal, 2008: 183). } \\
\text { (Luçşe umirat v pole, da ne } v \text { yame!) } \\
\text { Meydanda ölmek daha iyi, ama çukurda değil! }\end{array}$ & $\begin{array}{l}\text { Besser geflohen als } \\
\text { gestorben. } \\
\text { (Beyer ve Beyer, 1989: 88) } \\
\text { Kaçmak ölmekten iyidir. }\end{array}$ \\
\hline
\end{tabular}

$\mathrm{Bu}$ atasözlerinin temelinde bakıldığında ise her iki toplumun korkaklığa bakış açısındaki fark dikkat çekmektedir. Rus toplumunda Tanrı'dan başka kimseden korkulmaması üzerine vurgu yapılırken; Alman toplumunda "senden korkandan kork" diyerek karşılık bulmuştur. Aynı şekilde savaş meydanından kaçmaktansa ölmeyi yeğleyen Rus toplumu, kahramanca ölmenin daha iyi olduğunu belirtmiştir. Alman atasözünde ise tam tersine ölmektense kaçmanın daha mantıklı bir hareket olduğu ifade edilmiştir.

Adres

İstanbul Medeniyet Üniversitesi, Eğitim Bilimleri Fakültesi, Türkce ve Sosyal Bilimler Eğitimi Bölümü, Türkce Ĕgitimi ABD Cevizli Kampüsü, Kartal-İstanbul/TÜRKIYE e-posta: editor@rumelide.com
Address

İstanbul Medeniyet University, Faculty of Education Sciences,

Turkish and Social Scinces Education, Turkish Language Teaching

Education, Cevizli Campus, Kartal-İstanbul /TURKEY

e-mail: editor@rumelide.com 
Cesaret ve korku- korkaklık içerikli Rusça ve Almanca atasözleri benzer ve farklı yönleriyle karşılaştırmalı bir biçimde verilmeye çalışılmıştır. Bunun dışında Almancada ve Rusçada kendi içinde öne çıkan atasözleri ayrı ayrı tasnif edilmeye çalışılmıştır.

Tablo 6. Cesaret kavramı çerçevesinde milli kültürü yansıtan Almanca atasözleri

\begin{tabular}{|l|}
\hline Almanca \\
\hline Wer zu viel wagt, verliert alles (Beyer ve Beyer, 1989: 34). \\
Kim çok cesaret ederse her şeyi kaybeder. \\
\hline Böser Mut macht böses Blut (Beyer ve Beyer, 1989: 182). \\
Kötü cesaret kötü kan yapar. \\
\hline Wagen gewinnt, wagen verliert (Kirchberger, 1986: 114). \\
Cesaret etmek kazanır, cesaret etmek kaybeder. \\
\hline Angreifen kann jeder, aber der Mutige erwartet's (Kirchberger, 1986: 20). \\
Herkes saldırabilir, ama cesur bekler. \\
\hline
\end{tabular}

Almancada kendi içinde cesaret üzerine incelenen atasözlerinde kontrollü ve bilinçli cesarete vurgu yapıldığı gözlemlenmiştir. Alman halk bilincinde iyi cesaret ve kötü cesaret kavramı belirmiştir. Kontrolsüz ve bilinçsizce gösterilen cesaretin kaybettireceğine vurgu yapılmıştır.

Tablo 7. Korku - kaçma ikilemini vurgulayan Almanca atasözleri

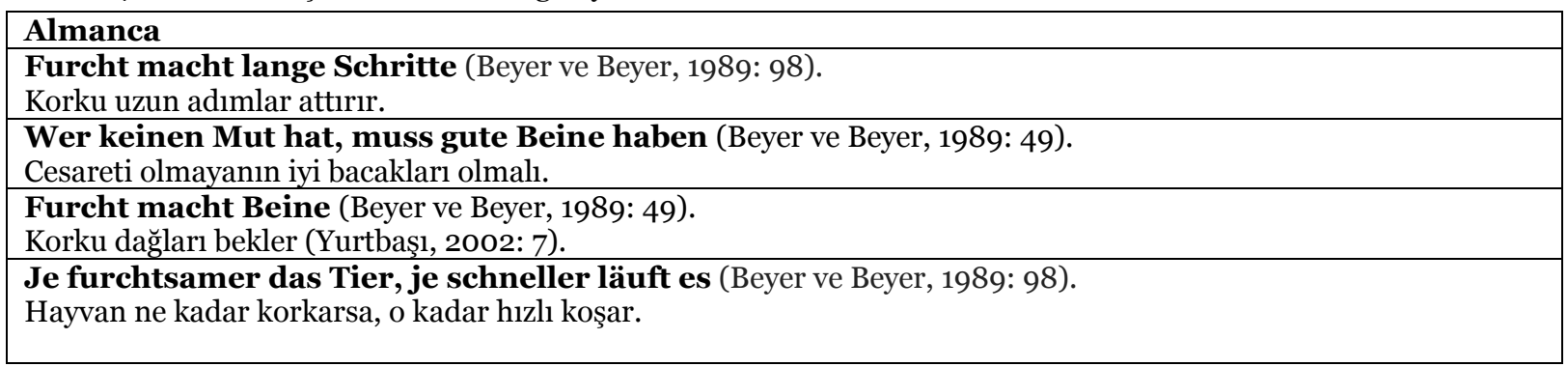

Almanca söz varlığında cesareti olmayan korkak insanların kaçmaya meyil ettiğini belirten atasözlerine rastlanmıștır.

Tablo 8. Cesaret kuşananın kılıç kuşanandan daha üstün olduğunu vurgulayan atasözleri

\begin{tabular}{|l|}
\hline Almanca \\
\hline Mut kämpft ohne Degen (Kirchberger, 1986: 83). \\
Cesaret kılıçsı savaşır. \\
\hline Ein tapferer Mann braucht keinen langen Degen (Kirchberger, 1986: 106). \\
Cesur bir adamın uzun bir kılıca ihtiyacı yoktur. \\
\hline Je tapferer Mann, je kürzer Degen (Beyer ve Beyer, 1989: 286). \\
Adam ne kadar cesursa kılıcı o kadar kısa olur. \\
\hline Besser des Tapferen Blick als des Feigen Schwert (Leineweber, 2018: 50). \\
Cesurun bakışı korkağın kılıcından daha iyidir. \\
\hline
\end{tabular}

Belirtilen atasözlerin ışığında cesaretin silahın, mühimmatın önüne geçtiğine, hatta silahı olup cesareti olmayan bir savaşçının etkisiz olduğunun altı çizilmiştir.

Tablo 9. Milli kültürel özellikleri yansitan Rusça atasözleri

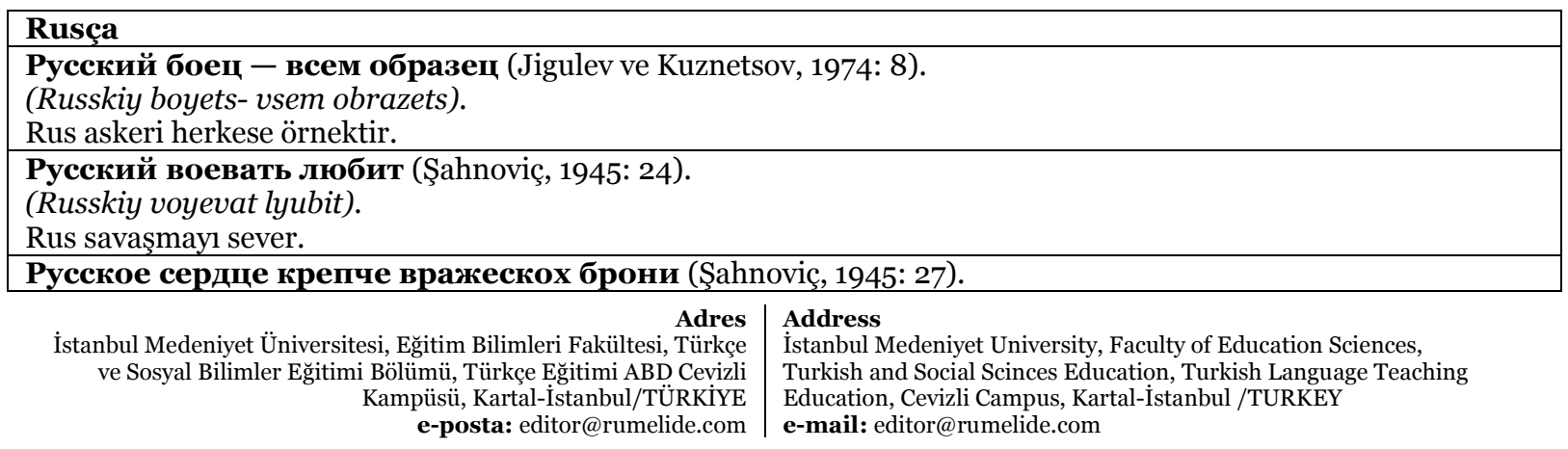


(Russkoe serdtse krepçe vrajeskoh broni).

Rus kalbi düșman zırhından sağlamdır.

Славна богатырями земля русская (Şahnoviç, 1945: 23).

(Slavna bogatryami zemlya russkaya).

Rus toprağı kahramanlarla doludur.

Смелый сокол в бою не дрогнет (Şahnoviç, 1945: 26).

(Smeliy sokol $v$ boyu ne drognet).

Cesur şahin muharebede üşümez.

Умелому воину зима не помеха (Jigulev ve Kuznetsov, 1974: 14).

(Umelomu voinu zima ne pomeha).

Cesur askere kış engel değildir.

Rusça söz varlığında ise cesaret ve korku- korkaklık kavramı üzerine milli kültürel özellikleri yansıtan, Rus askerlerinin özelliklerine vurgu yapan atasözlerine rastlanılır. Rusların savaştaki cesaretinin, korkusuzluğunun ve kahramanlığının altı çizilmiştir.

\section{Sonuç}

Folklorun bir parçası olan atasözleri, bir milletin tarihinden, kültür ekolojisinden ve servetinden bir kesit sunmaktadır. Rus ve Alman toplumların bakış açısına göre cesaret ve korku- korkaklık kavramlarını içeren atasözlerini inceleyen bu çalışmada anlam ve içerik açısından benzer atasözlerinin çoğunlukta olduğu tespit edilmiştir. Her iki halkın atasözlerinden yola çıkarak cesur olanın yüceltildiği, korkakların ise aşağılandığı bir dünya görüşü ortaya çıkmıştır. Genel itibariyle cesur olunması gerektiği üzerine salık verilirken, Alman toplumunun cesarete bakış açısı Rus toplumuna göre farklılık göstermektedir. Alman atasözlerinden "Kim çok cesaret ederse her şeyi kaybeder.”, "Kötü cesaret kötü kan yapar.”, "Cesaret etmek kazanır, cesaret etmek kaybeder”, "Herkes saldırabilir, ama cesur bekler.” yola çıarak Alman toplumunun kontrollü ve bilinçli cesareti savunduğunu söyleyebiliriz.

İncelenen sözlük çalışmaları sonucunda her iki toplumun atasözlerinde tavşanın korkaklığı sembolize ettiği tespit edilmiştir. Bununla birlikte elde edilen atasözlerinde Rus ve Alman toplumunda cesur bir biçimde savaşmaya kutsiyet atfedildiği sonucuna varılmıştır.

\section{Kaynakça}

Ahanov, K. (2013). Dilbilimin Esasları (Çev. M. Ceritoğlu) Ankara: Türk Dil Kurumu Yayınları.

Alefirenko, N.F. ve Semenenko, N.N. (2009). Frazeologiya i Paremiologiya. Moskova: Flinta.

Basko, N.V. (2019). Lingvokul'turnıy kontsept "maksimalizm" v russkoy yazıkovoy kartine mira, Prepodavatel' XXI vek, 2 (2), s.346- 359.

Bausinger, H. (1968). Formen der Volkspoesie. Berlin: Erich Schmidt Verlag.

Beyer, H. ve Beyer, A. (1989). Sprichwörterlexikon. Leipzig: Bibliographisches Institut.

Bodrova, Yu. V. (2007). Russkie Poslovitsı i Pogovorki i ih Angliyskie Analogi. Moskova: AST.

Butzer, G. ve Jacob, J. (2008). Metzler Lexikon literarischer Symbole. Stuttgart: J.B. Metzler Verlag.

Dal, V.İ. (2008). Poslovitsı russkogo naroda. M: Astrel'.

Frey, D. (2017). Psychologie der Sprichwörter. Berlin-Heidelberg: Springer Verlag.

Gogol, N.V. (1952) V çem je, nakonets, suşçestvo russkoy poezii, i v çem ee osobennost'. Polnoe sobranie soçineniy içinde (s.369- 409). 8.Cilt Moskova; Leningrad: AN SSSR.

Adres

İstanbul Medeniyet Üniversitesi, Eğitim Bilimleri Fakültesi, Türkce ve Sosyal Bilimler Eğitimi Bölümü, Türkçe Eğitimi ABD Cevizli Kampüsü, Kartal-İstanbul/TÜRKIYY e-posta: editor@rumelide.com
Address

Istanbul Medeniyet University, Faculty of Education Sciences,

Turkish and Social Scinces Education, Turkish Language Teaching

Education, Cevizli Campus, Kartal-İstanbul /TURKEY

e-mail: editor@rumelide.com 
Golovnya, A.İ. ve Çjan, Ç. (2012). Kontseptı smelost', otvaga i trusost' v russkoy i kitayskoy naivnıh yazıkovıh kartinah mira. Karpovskie nauçnıe çteniya içinde (s.63-66). Minsk: Belorusskiy Dom peçati.

Herder J. G. (1877). Werke. Bd. II, Berlin: Weidmann.

Humboldt, v. W. (1880). Über die Verschiedenheit des menschlichen Sprachbaues und ihren Einflu $\beta$ auf die geistige Entwicklung des Menschengeschlechts Zweiter Band, Berlin: Verlag von S. Calvary \& Co.

Humboldt, v. W. (1995). Schriften zur Sprache. Stuttgart: Reclam.

Jigulev, A.M. ve Kuznetsov, N.P. (1974). Za Kray Svoy Nasmert' Stoy. Poslovitsı i Pogovorki Narodov SSSR. Moskva: Voenizdat.

Jukov, V. P. (1991). Slovar russkih poslovits i pogovorok: Okolo 1200 poslovits i pogovorok. Moskva: Russkiy yazık.

Karstedt, L. V. (2004). Sprache und Kultur Eine Geschichte der deutschsprachigen Ethnolinguistik Doctoral Dissertation, Hamburg University Institute of Philosophy, Hamburg.

Kaufmann, A. (1991). Über die Tapferkeit des Herzens. ARSP: Archiv für Rechts-und Sozialphilosophie/Archives for Philosophy of Law and Social Philosophy, 77(1), 1-16.

Kirchberger, J. H. (1986). Das grosse Sprichwörterbuch. München: Lexikographisches Institut.

Krasnıh, V.V. (2002). Etnolingvistika i lingvokul'turologiya. Moskova: Gnozis.

Kuper, DJ. (1995). Entsiklopediya simvolov. Moskova: Zolotoy Vek.

Kuße H. (2012). Kulturwissenschaftliche Linguistik. Göttingen: Vandenhoeck \& Ruprecht.

Kuusi, M. (1957). Parömiologische Betrachtungen. Helsinki: Suomalainen Tiedeakatemia.

Kuznetsova, A. Bez poslovitsı reç' ne molvitsya sbornik russkih poslovits. München: Ingenieur - und Preßebüro.

Leineweber, H. (2018). Die Weisheit auf der Gasse: Zusammenstellung und Erklärung von Sprichwörtern und sprichwörtlichen Redensarten. Hildesheim: Georg Olms Verlag.

Maslova, V.A. (2001). Lingvokul'turologiya. Moskva: Akademiya.

Potebnya, A.A. (1989). Mısl' i yazık. Moskva: Pravda.

Rıbnikova, M. A. (1961). Russkie poslovitsı i pogovorki. Moskva: İzdatelstvo akademii nauk SSSR.

Röhrich, L. ve Mieder, W. (1977). Sprichwort (Vol. 154). Stuttgart: Metzler.

Seiler, F. (1918). Das deutsche Sprichwort. Berlin: KJ Trübner.

Şahnoviç, M. (1945). Voennıe Poslovitsı Russkogo Naroda. Lenigrad: Leningradskoe GazetnoeJurnal'noe i Knijnoe İzdatel'stvo.

Ter- Minasova, S.G. (2000). Yazık i Mejkul'turnaya Kommunikatsiya. Moskva: MGU.

Tolstoy, N. İ. (1990). Yazık i kul'tura(nekotorıe problemı slavyanskoy etnolingvistiki). Zeitschrift für Slavische Philologie, 50 (2), s. 238-253.

Tresidder, Dj. (1999). Slovar' Simvolov. Moskova: Grand.

Yurtbaşı, M. (2002). Alman Atasözleri ve Türkçe Karşllıkları. İstanbul: Metin Yurtbaşı.

\footnotetext{
Adres $\mid$ Address

İstanbul Medeniyet Üniversitesi, Eğitim Bilimleri Fakültesi, Türkçe İstanbul Medeniyet University, Faculty of Education Sciences, ve Sosyal Bilimler Eğitimi Bölümü, Türkce Eğitimi ABD Cevizli Turkish and Social Scinces Education, Turkish Language Teaching Kampüsü, Kartal-İstanbul/TÜRKIYE $\quad$ Education, Cevizli Campus, Kartal-İstanbul /TURKEY e-posta: editor@rumelide.com $\mid$ e-mail: editor@rumelide.com
} 